\title{
A Novel Hammer-Shaped UWB Antenna with Triple Notched-Band for Rejecting RLS, WLAN and XSCS bands
}

\author{
Hari Shankar Mewara ${ }^{1}$, Deepak Jhanwar², Mahendra Mohan Sharma ${ }^{3}$, \\ Jitendra Kumar Deegwal ${ }^{4}$
}

\author{
${ }^{1,4}$ Department of Electronics Instrumentation and Control Engineering, Government Engineering College Ajmer, India \\ ${ }^{1,2}$ Department of Electronics and Communication Engineering, Government Engineering College Ajmer, India \\ ${ }^{3}$ Department of Electronics and Communication Engineering, Malaviya National Institute of Engineering and Technology, \\ Jaipur, India \\ *Hari Shankar Mewara, E-mail: hsmewara@gmail. com
}

\begin{abstract}
A novel hammer-shaped UWB printed antenna with triple notched stop bands is presented and fabricated on FR-4 substrate with size of $40 \times 40 \times 1.6 \mathrm{~mm}^{3}$. The proposed antenna is composed of hammer-shaped patch with Cshaped slot, U-shaped slot on feed line, and inverted stepped notch and bevel edges with pair of L-shaped slots in partial ground plane. The fabricated antenna is tested and obtained impedance bandwidth $2.89-11.6 \mathrm{GHz}$ with three notched stop bands $3.15-3.7 \mathrm{GHz}, 5.45-6.8 \mathrm{GHz}$, and 7.5$8.8 \mathrm{GHz}$, for radiolocation system (RLS), wireless local area networks (WLAN), and X-band satellite communication system (XSCS) bands, respectively. Moreover, the antenna result shows omnidirectional radiation pattern, average gain of $3.10 \mathrm{dBi}$ over the whole UWB band except at the notched frequency bands.
\end{abstract}

\section{Introduction}

Ultra-wideband (UWB) spectrum 3.1-10.6 GHz was allowed by US Federal Communications Commission (FCC) for commercial communication application in 2002 [1]. For UWB communication, there is a need of antenna that operates in UWB range. So, UWB antenna is desirable which presents attractive features such as small size, simple structure, omnidirectional pattern stability, and low fabrication cost. Due to these features UWB antenna is an active research topic in recent years for academia and industry people. The various printed UWB antenna are reported [2,3] and prevalent methods to increase impedance bandwidth are introduction of steps and triangle cut in partial ground plane [2, 3]. In the UWB band, there are bands such as radiolocation system (RLS) band (3.1-3.7 $\mathrm{GHz}$ ) as per US National table of frequency allocation, wireless local area network (WLAN) for IEEE 802.11a $(5.15-5.825 \mathrm{GHz})$, and X-band satellite communication system (XSCS) band (7.3-8.4 GHz) exists which can create interference with UWB system. Hence, UWB antennas with single [6-9, 13], dual [10-13], and triple [14-18] notched bands are reported.
In this paper, a novel hammer-shaped UWB printed antenna with triple notched stop bands is presented. The triple notched stop bands are achieved by etching a Cshaped slot on the patch for RLS band, a pair of L-shaped slot in partial ground plane for WLAN band, and U-shaped slot on feed line for XSCS band. The purpose of placing these three slots at different positions is to reduce mutual coupling which is undesirable part of any UWB antenna with notched band characteristics. Embedding inverted stepped notch in the partial ground plane improves impedance characteristics at higher frequency side. CST Microwave studio (ver. 2014) is used to design and simulate the proposed etched slot-type hammer shaped UWB antenna.

Step by step antenna design process, frequency band suppression methodology, experimental results, and conclusion are presented in section 2, 3, 4, and 5, respectively.

\section{Basic UWB Antenna Design and Analysis}

The hammer-shaped basic UWB antenna top and bottom view is shown in Fig. 1 (a) and (b), respectively. The designed antenna is printed on a FR-4 substrate having dielectric constant 4.3 , loss tangent of 0.025 , and thickness of $1.6 \mathrm{~mm}$. The hammer-shaped antenna has a partial ground having length (LG) $13.3 \mathrm{~mm}$, and is fed by a $50 \Omega$ microstrip line. To match this $50 \Omega$ characteristic impedance, the width (WF) of feed line is taken as $4 \mathrm{~mm}$. By introducing inverted stepped notch and beveled edges in partial ground plane, the impedance bandwidth at higher frequency side is improved because of improvement in capacitive coupling tuning between the hammer-shaped patch and ground plane [3]. Fig. 2 shows the simulated VSWR for basic hammer-shaped antenna without inverted steps and bevel cut in the partial ground plane is 3.39-9.67 $\mathrm{GHz}$ and has improved to $3.39-11.08 \mathrm{GHz}$ by introducing inverted steps and bevel cut in the partial ground plane. The labeled optimized antenna parameters are given in Table 1. 


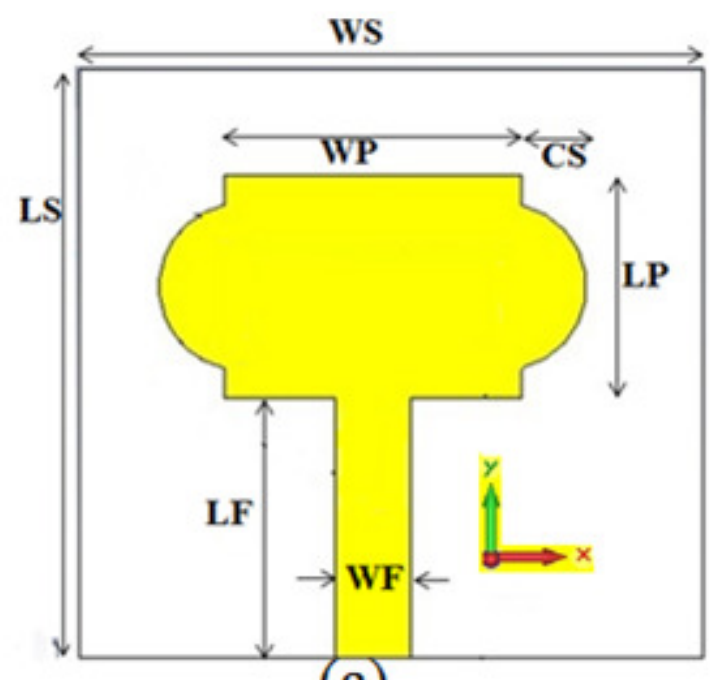

(a)

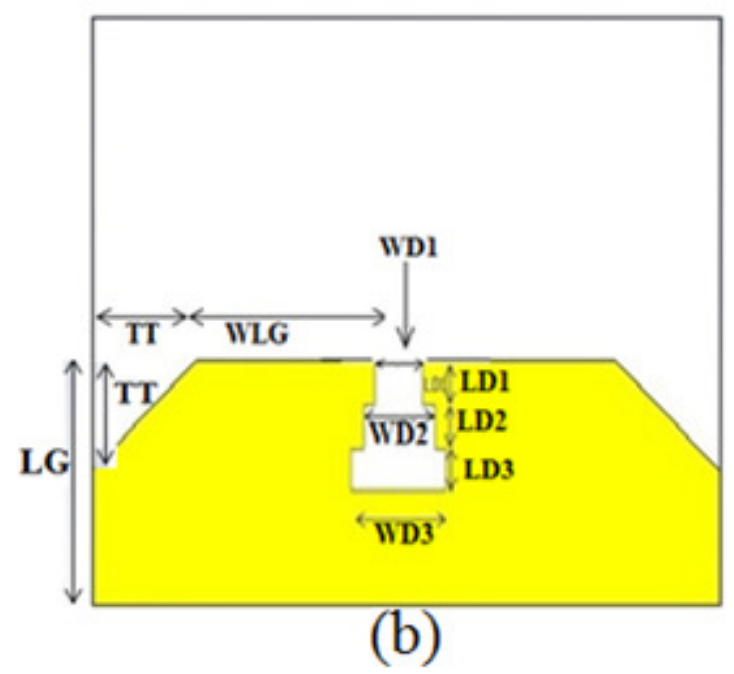

Figure 1: Basic hammer-shaped UWB antenna (a) top view (b) bottom view.

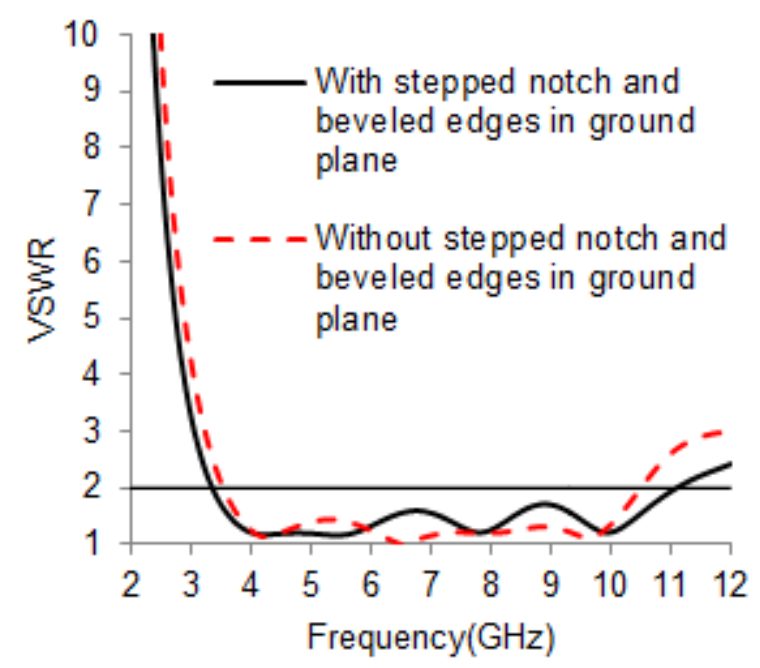

Figure 2: Comparison of VSWRs against frequency for basic hammer-shaped UWB antenna with and without stepped notch and beveled edges.
Table 1: Optimized parameters for basic hammer-shaped antenna.

\begin{tabular}{cccc}
\hline parameter & size $(\mathrm{mm})$ & parameter & size $(\mathrm{mm})$ \\
\hline CS & 3.5 & TT & 6 \\
\hline HS & 1.6 & WD1 & 2 \\
\hline LD1= LD2 & 1.3 & WD2 & 3 \\
\hline LD3 & 1.3 & WD3 & 4 \\
\hline LF & 14 & WF & 4.03 \\
\hline LG & 13.3 & WLG & 14 \\
\hline LP & 12 & WP & 16 \\
\hline LS & 40 & WS & 40 \\
\hline
\end{tabular}

\section{Frequency Bands Suppression Methodology}

Three different types of slots (i.e., band stop resonators) are etched at three different locations in the proposed hammershaped antenna. The length of slot $\left(\mathrm{L}_{\text {slot }}\right)$ for each band stop resonator would be half of guided wavelength $\left(\lambda_{\mathrm{g}}\right)$. The length of slot $\left(\mathrm{L}_{\text {slot }}\right)$ and effective dielectric constant $\left(\varepsilon_{\text {eff }}\right)$ can be calculated by (1), (2) and (3) as:

$$
\begin{aligned}
& L_{\text {slot }}=\left(\frac{\lambda_{g}}{2}\right), \\
& \lambda_{g}=\left(\frac{c}{f_{n}}\right) \times\left(\frac{1}{\sqrt{\varepsilon_{\text {eff }}}}\right), \\
& \varepsilon_{\text {eff }} \approx\left(\frac{\varepsilon_{r}+1}{2}\right),
\end{aligned}
$$

where $c$ is speed of light $\left(3 \times 10^{8} \mathrm{~m} / \mathrm{s}\right), f_{n}$ is the notch centre frequency, $\varepsilon_{r}$ is the dielectric constant of the substrate. It can be observed that the C-shaped slot in patch has the largest length and is acting as band stop resonator for RLS band notch while shortest length is of U-shaped slot placed in feed for XSCS band. Design of single band notch UWB antennas are as follows:

\subsection{RLS Band-Notched UWB Antenna}

To suppress a RLS band $(3.1-3.7 \mathrm{GHz})$ with chosen centre notch frequency $f_{n}$ of $3.4 \mathrm{GHz}$, an inverted C-shaped slot (named as slot-A) of calculated length $\lambda_{\mathrm{g}} / 2$ value by (2) and (3) is loaded in hammer-shaped patch as shown in Fig. 3 (a) with its labeled parameters. The voltage standing wave ratio (VSWR) plot for Antenna-A is shown in Fig. 4. The simulated centre notch frequency at $3.25 \mathrm{GHz}(3.07-3.68$ $\mathrm{GHz}$ ) is observed with optimized length of slot- $\mathrm{A}, \mathrm{L}_{\text {slot- }}=$ $\mathrm{WA}+2 \mathrm{LA}+\mathrm{TA}=31.3 \mathrm{~mm}$, where $\mathrm{WA}=15 \mathrm{~mm}, \mathrm{TA}=$ $0.3 \mathrm{~mm}$, and LA $=8 \mathrm{~mm}$. This optimized value is close to calculated value of $27.06 \mathrm{~mm}$.

\subsection{WLAN Band- Notched UWB Antenna}

To suppress a WLAN band $(5.15-5.825 \mathrm{GHz})$ with chosen centre notch frequency $f_{n}$ of $5.5 \mathrm{GHz}$, a pair of L-shaped slot (named as slot-B) of calculated length $\lambda_{\mathrm{g}} / 2$ value by (2) and (3) is loaded in ground plane of hammer-shaped antenna as shown in Fig. 3 (b) with labeled parameters. The 
VSWR plot for Antenna-B is shown in Fig. 4. The simulated centre notch frequency at $5.6 \mathrm{GHz}(5.13-5.82$ $\mathrm{GHz})$ is observed with optimized length of slot-B, $\mathrm{L}_{\text {slot-B }}=$ $\mathrm{WB}+\mathrm{LB}+\mathrm{TB}=18.2 \mathrm{~mm}$, where $\mathrm{WB}=10 \mathrm{~mm}, \mathrm{LB}=8$ $\mathrm{mm}, \mathrm{TB}=0.2 \mathrm{~mm}, \mathrm{SBG}=1 \mathrm{~mm}$, and $\mathrm{SBLR}=6 \mathrm{~mm}$. This optimized value is close to calculated value of $16.73 \mathrm{~mm}$.

\subsection{X-Band Satellite Communication System (XSCS) Band-Notched UWB Antenna}

To suppress a XSCS band $(7.25-8.4 \mathrm{GHz})$ with chosen centre notch frequency $f_{n}$ of $7.8 \mathrm{GHz}$, a U-shaped slot (named as slot-C) of calculated length $\lambda_{\mathrm{g}} / 2$ value by (2) and (3) is inserted in feed line of hammer-shaped antenna as shown in Fig. 3 (c) with labeled parameters. The VSWR plot for Antenna-C is shown in Fig. 4. The simulated centre notch frequency at $7.75 \mathrm{GHz}(7.25-8.35 \mathrm{GHz})$ is observed with optimized length of slot-C, $\mathrm{L}_{\text {slot-C }}=\mathrm{WC}+2 \mathrm{LC}+\mathrm{TC}=$ $13.34 \mathrm{~mm}$, where $\mathrm{LC}=4.9 \mathrm{~mm}, \mathrm{WC}=3.34 \mathrm{~mm}$, and $\mathrm{TC}=$ $0.2 \mathrm{~mm}$. This optimized value is close to calculated value of $11.79 \mathrm{~mm}$.

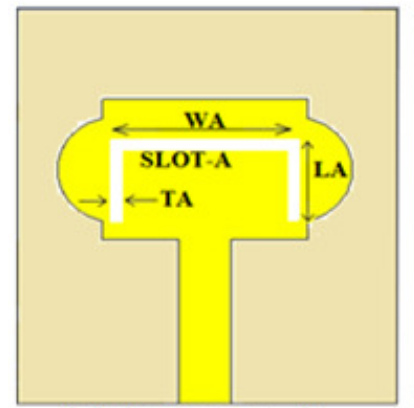

(a)Antenna-A

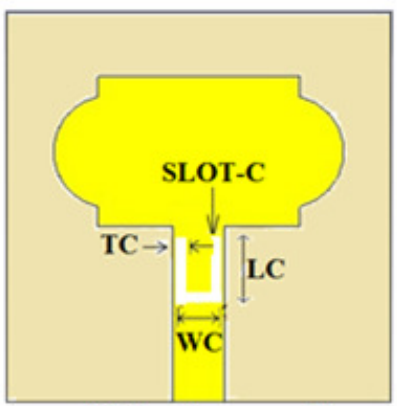

(c)Antenna-C

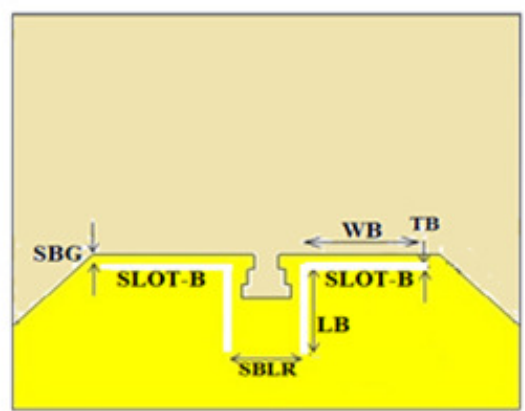

(b)Antenna-B

Figure 3: (a) Antenna-A with slot-A in patch, (b) Antenna-B with pair of slot-B in ground plane, and (c) Antenna-C with slot- $\mathrm{C}$ in feed line.

\section{Triple Band-Notched UWB Antenna: Results and Discussion}

After getting the desired notch bands individually i.e. using a C-shaped slot for RLS band, a pair of L-shaped slots for WLAN band, and a U-shaped slot for XSCS-band, these three slot notch elements are etched on a single hammershaped antenna (Antenna-D) to get triple notched stop bands. The positions of slots finalized are slot-A on radiating patch element, a pair of slot-B on partial ground plane and a slot-C on feed line. Reason to place three slots at three different locations on antenna is to avoid mutual interference among notched bands. The geometry of the proposed hammer-shaped Antenna-D including radiating element and ground plane with three slots is shown in Fig. 5 and fabricated proposed hammer-shaped Antenna-D is shown in Fig. 6.

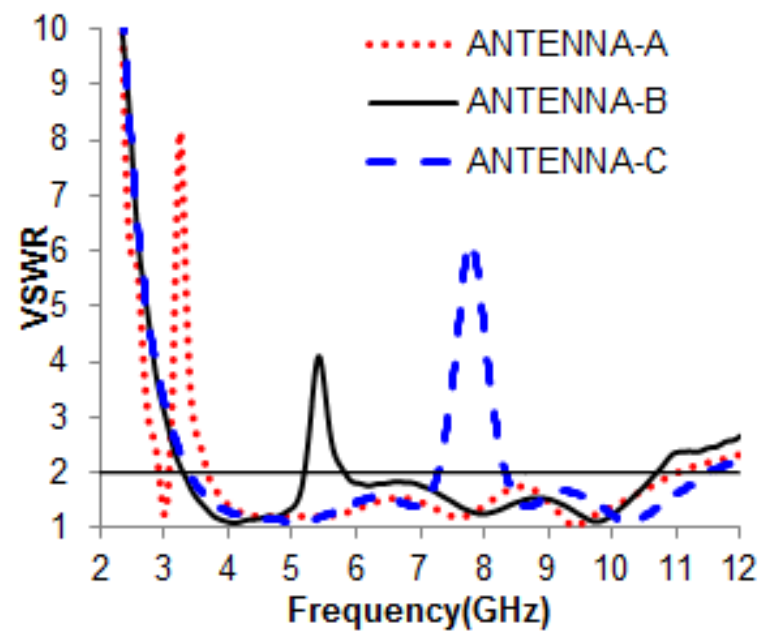

Figure 4: Comparison of VSWR plots for Antenna-A, Antenna-B, and Antenna-C of Fig. 3.

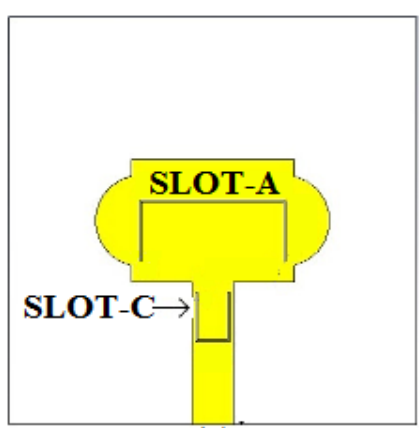

(a)

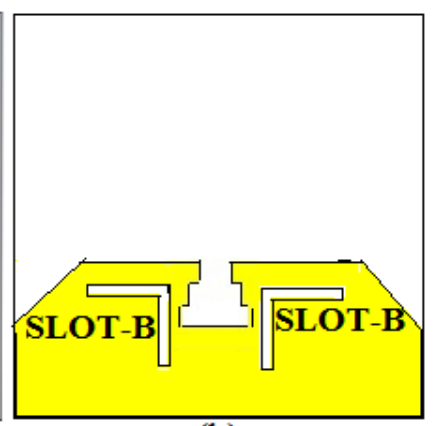

(b)
Figure 5: Proposed triple band notch hammer-shaped Antenna-D geometry (a) top side, and (b) bottom side.

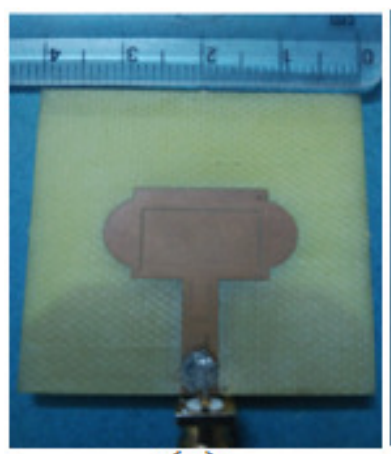

(a)

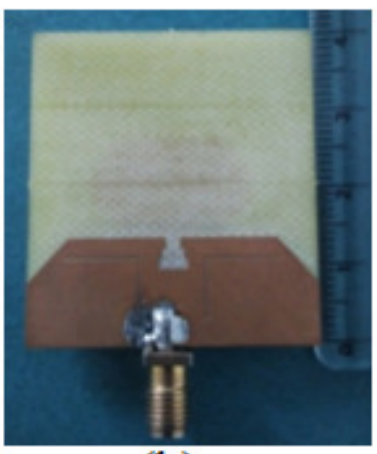

(b)
Figure 6: Proposed fabricated triple band hammer-shaped Antenna-D (a) top side, and (b) bottom side. 


\subsection{Parametric Study}

To study the analysis/effect of various parameters on bandwidth of notch bands, one parameter at a time is varied. For simplicity total length $\mathrm{L}_{\text {slot-A }}, \mathrm{L}_{\text {slot- } \mathrm{B}}$, and $\mathrm{L}_{\text {slot-C }}$ of each slot $\mathrm{A}, \mathrm{B}$, and $\mathrm{C}$ are varied and its variation on VSWR is plotted in Fig. 7 (a), (b), and (c), respectively. As length of slot-A $\mathrm{L}_{\text {slot-A }}$ is increased from 22.3 to $24.3 \mathrm{~mm}$ in steps each of $1 \mathrm{~mm}$ then centre of notch frequency of slot length for RLS band notch is shifted from 3.43 to $3.07 \mathrm{GHz}$ while the second and third notch bands remains unchanged. The theoretical reason for this is the fact that notch centre frequency is inversely proportional to the length of slot $\mathrm{L}_{\text {slot- }}$ A so as length of slot increases then centre notch frequency shifts towards lower frequency side by (1) and (2) while the same can be verified from the VSWR plot. Similar trends follow for increase in length of slot-B $\mathrm{L}_{\text {slot-B }}$ from 17.7 to $19.7 \mathrm{~mm}$ and slot-C $\mathrm{L}_{\text {slot-C }}$ from 4.6 to $5.2 \mathrm{~mm}$ for WLAN and XSCS band notches, respectively.

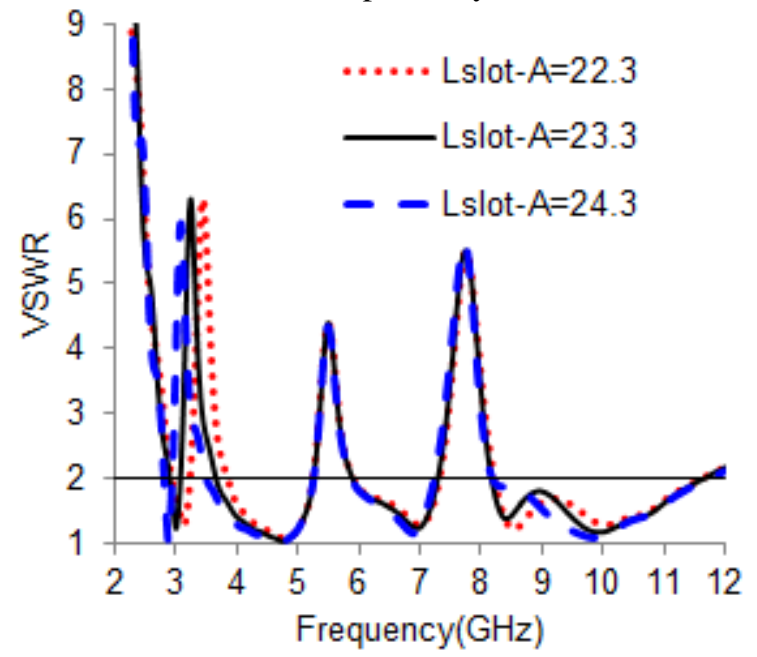

Figure 7: (a) VSWR curve for variation in length of slot-A for proposed Antenna-D.

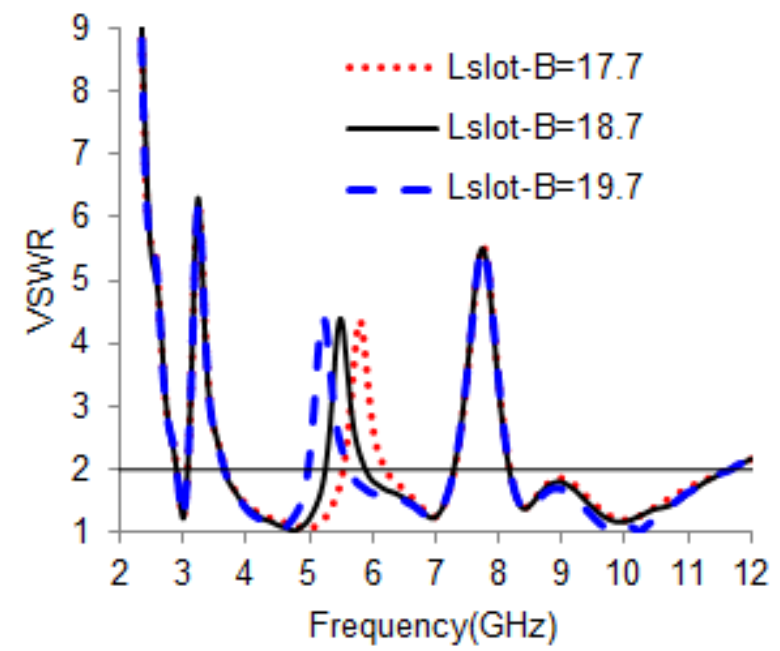

Figure 7: (b) VSWR curve for variation in length of slot-B for proposed Antenna-D.

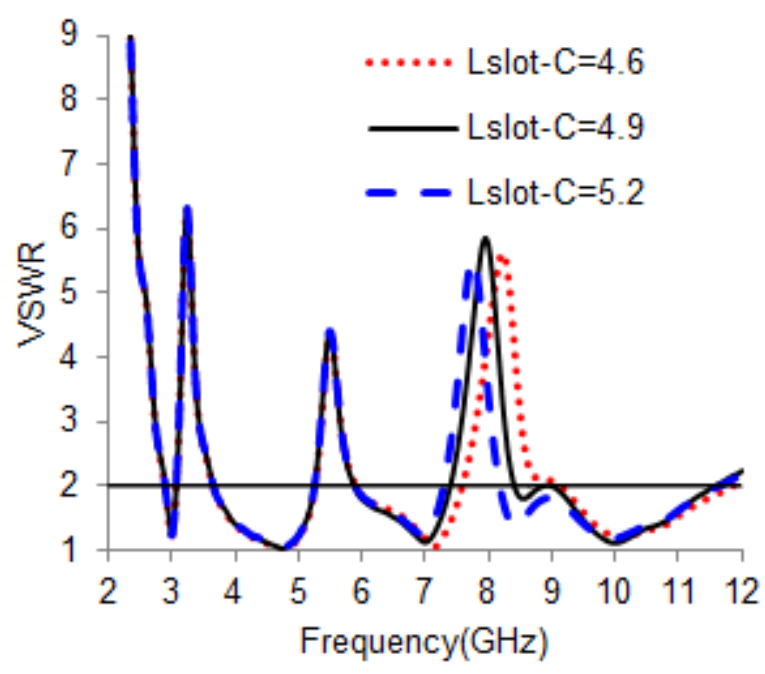

Figure 7: (c) VSWR curve for variation in length of slot-C for proposed Antenna-D.

It is also observed that the variation in length of one slot negligibly affect the bandwidth and shape of other band notches because different location of slots helps in minimizing the mutual coupling among the elements. Therefore, the total length of $\mathrm{L}_{\text {slot }-\mathrm{A}}, \mathrm{L}_{\text {slot }-\mathrm{B}}$, and $\mathrm{L}_{\text {slot-C }}$ is taken to be $22.3 \mathrm{~mm}, 18.7 \mathrm{~mm}$, and $4.9 \mathrm{~mm}$ for designing the hammer-shaped band notched antenna. It may also be concluded that the centre notch frequency of individual band can be controlled by respective length of $\mathrm{L}_{\text {slot-A }}, \mathrm{L}_{\text {slot-B }}$, and $\mathrm{L}_{\text {slot-C. }}$. Thus bandwidth of each notched band can be independently adjusted by varying individual length and location of slots.

\subsection{VSWR}

Agilent PNA-L network analyzer model no. N5234A was used to measure VSWR characteristics of proposed hammer-shaped Antenna-D. Fig. 8 shows the simulated and measured VSWR curve of the proposed Antenna-D.

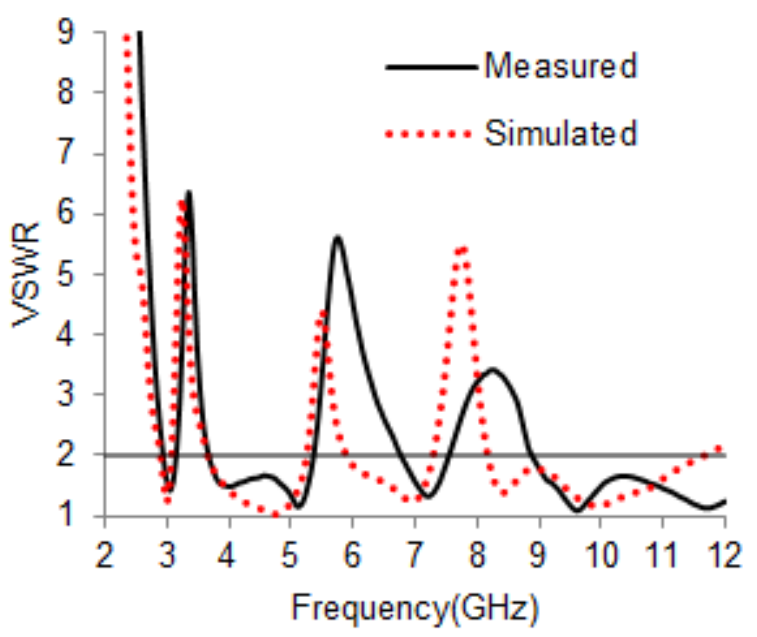

Figure 8: Measured and simulated VSWR for proposed hammer-shaped Antenna-D.

The simulated and measured VSWR results show good agreement with slight variations; the reason for variations 
can be accounted for fabrication errors, not consideration of SMA connector during antenna design simulation. Table 2 shows comparison of the allocated bandwidth, simulated and measured notch bandwidth result (VSWR $>2$ ) for three stop band notches while optimized length of each slot as percentage of guided wavelength $\left(\lambda_{\mathrm{g}}\right)$ for three band notches is also presented.

Table 2: Comparison of various characteristics for triple band notches for Antenna-D.

\begin{tabular}{cccc}
\hline $\begin{array}{c}\text { Band notch } \rightarrow \\
\text { Parameters } \downarrow\end{array}$ & RLS & WLAN & XSCS \\
\hline $\begin{array}{c}\text { Centre notch } \\
\text { frequency }(\mathrm{GHz})\end{array}$ & 3.4 & 5.5 & 7.8 \\
\hline $\begin{array}{c}\text { Allocated } \\
\text { bandwidth }(\mathrm{GHz})\end{array}$ & $3.1-3.7$ & $5.15-5.85$ & $7.25-8.4$ \\
\hline $\begin{array}{c}\text { Simulated band } \\
\text { notch BW(GHz) }\end{array}$ & $3.05-3.67$ & $5.25-6$ & $7.3-8.3$ \\
\hline $\begin{array}{c}\text { Measured band } \\
\text { notch BW(GHz) }\end{array}$ & $3.15-3.7$ & $5.45-6.8$ & $7.5-8.8$ \\
\hline $\begin{array}{c}\text { Optimized } \\
\text { length of slot } \\
\left(\% \text { of } \lambda_{\mathrm{g}}\right)\end{array}$ & 54 & 54 & 53 \\
\hline
\end{tabular}

\subsection{Current Distributions}

Operating principle for RLS, WLAN and XSCS notched bands can be further explained by observing current distributions of the proposed hammer-shaped Antenna-D at centre notch frequency of each stop band as shown in Fig. 9 (a), (b), and (c), respectively. At 3.4 GHz, 5.5 GHz, and 7.8 $\mathrm{GHz}$, the current distribution is maximum observed along the slots $\mathrm{A}, \mathrm{B}$, and $\mathrm{C}$ etched on radiating patch, ground plane, and feed line, respectively. It is observed that opposite current flows in inner and outer part of all slots thus cancelling out each other and is the main cause for non-responsiveness of proposed Antenna-D at these three notch frequencies.

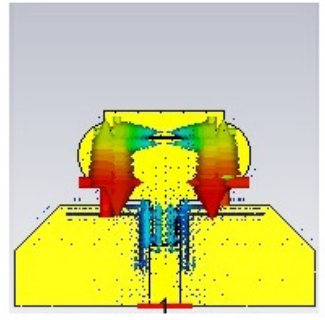

(a)

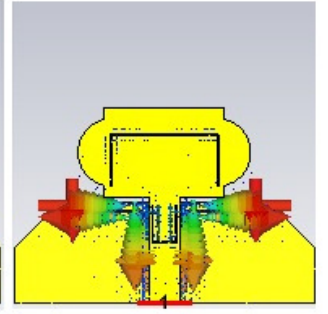

(b)

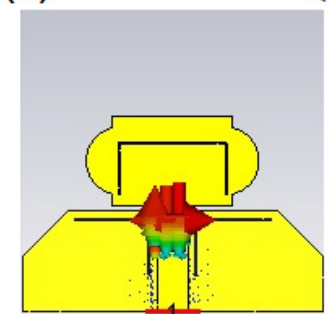

(c)

Figure 9: Current Distribution of proposed hammershaped Antenna-D at center notch frequency of (a) 3.5 $\mathrm{GHz}$, (b) $5.5 \mathrm{GHz}$, and (c) $7.8 \mathrm{GHz}$.

\subsection{Gain and Radiation Patterns}

The gain comparison of proposed hammer-shaped Antenna$\mathrm{D}$ and basic hammer-shaped UWB antenna is shown in Fig. 10. Gain variation of Antenna-D is $1.42-4.28 \mathrm{dBi}$ and average gain of $3.10 \mathrm{dBi}$ over entire UWB range except at notched bands is observed. The peak gain of the proposed hammer-shaped Antenna-D drops at three notched band centre frequencies $3.2 \mathrm{GHz}, 5.5 \mathrm{GHz}$, and $7.8 \mathrm{GHz}$ are -9.6 $\mathrm{dBi},-5.4 \mathrm{dBi}$, and $-8.8 \mathrm{dBi}$, respectively as expected and is evident from Fig. 10. The radiation pattern of the proposed hammer-shaped Antenna-D was measured in anechoic chamber with LB-10180 horn antenna as transmitting antenna and proposed Antenna-D as antenna under test (AUT). The measured radiation pattern along two principle (E- and $\mathrm{H}-$ ) planes at different resonating frequencies 3.1 $\mathrm{GHz}, 4.75 \mathrm{GHz}, 7 \mathrm{GHz}$, and $9.9 \mathrm{GHz}$ is shown in Fig. 11 (a), (b), (c), and (d), respectively. The proposed Antenna-D shows nearly omnidirectional radiation characteristics along the H-plane and dumbbell shaped along E-plane. At higher frequency, increase in cross polarization level is observed due to increasing horizontal surface components of the hammer-shaped Antenna-D.

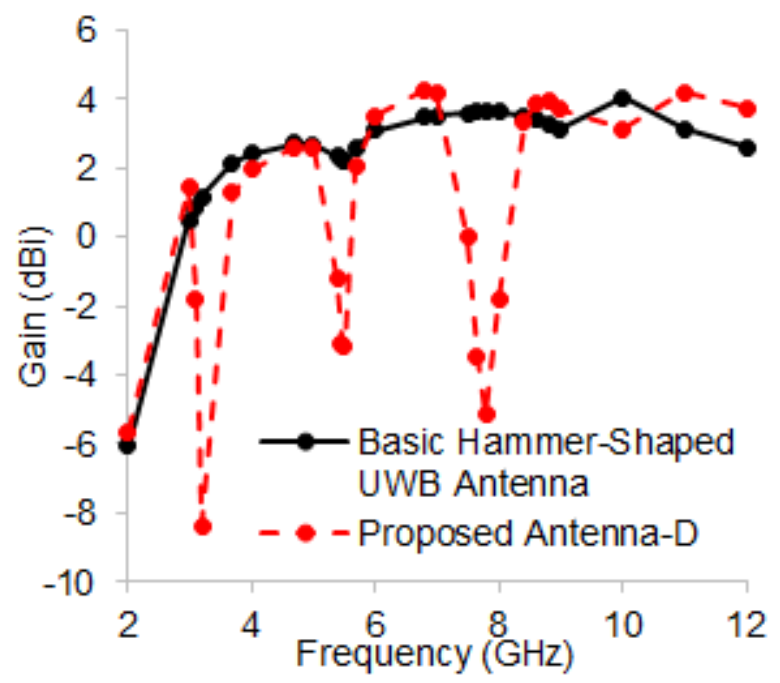

Figure 10: Gain comparison of proposed triple band notched hammer-shaped Antenna-D.

\section{Conclusions}

A novel proposed hammer-shaped printed antenna with triple notched stop bands is designed, fabricated and investigated. These notched bands with centre frequency at $3.4 \mathrm{GHz}(3.15-3.7 \mathrm{GHz}), 5.75 \mathrm{GHz}(5.45-6.8 \mathrm{GHz})$, and $8.15 \mathrm{GHz}(7.5-8.8 \mathrm{GHz})$ are obtained by incorporating a Cshaped slot on radiating element for RLS band, a pair of Lshaped slots are etched on ground plane to get WLAN band and U-shaped slot is introduced in the feed line for XSCS band. Each of the rejected frequency band can be controlled independently by adjusting total length of each slot. The proposed antenna shows omnidirectional radiation pattern over UWB range and average gain of $3.10 \mathrm{dBi}$ makes it suitable for practical UWB applications except RLS, WLAN and XSCS band. 


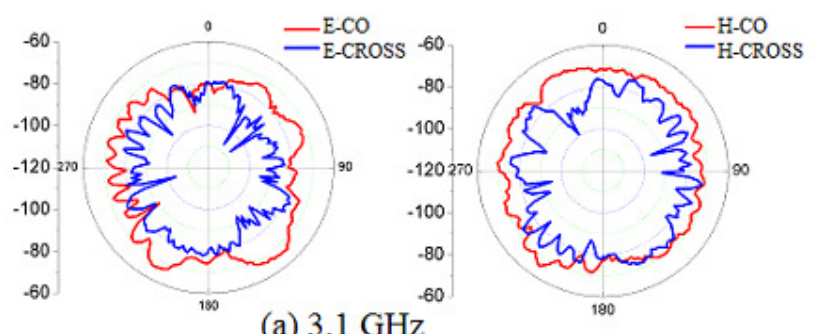

(a) $3.1 \mathrm{GHz}$
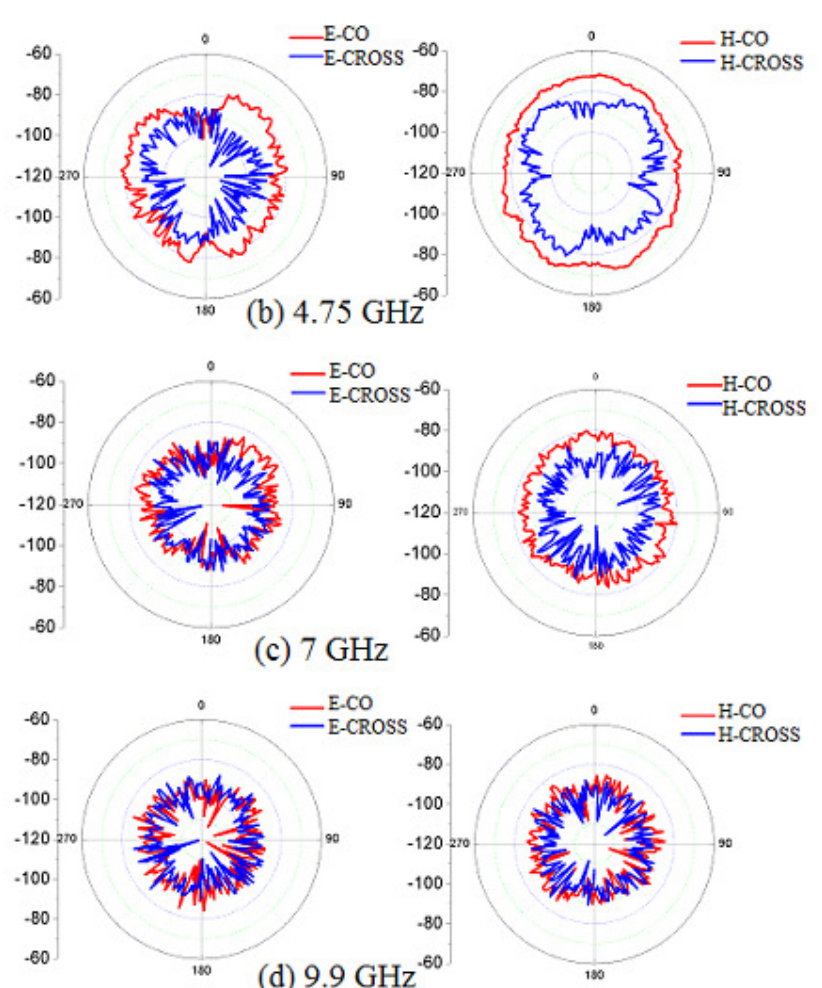

Figure 11: Measured E- and H-plane (co- and cross-pole) radiation pattern for hammer-shaped Antenna-D at various resonant frequencies.

\section{Acknowledgements}

We are grateful to Prof. Kumar Vaibhav Srivastava, Indian Institute of Technology, Kanpur, India and Government Mahila Engineering College, Ajmer, India for providing measurement facility of the fabricated antenna in their lab.

\section{References}

[1] X. Shen, M. Guizani, R.C. Qiu, T. Le-Ngoc, UltraWideband Wireless Communication and Networks, John Wiley \& Sons, England. 2006.

[2] J. Liang, L. Kuo, C.C. Chiau, X. Chen, C.G. Parini, Study of CPW-fed circular disc monopole antenna for ultra wideband applications, IEE Proc.-Microw. Antennas Propag. 152 (6): 520-526, 2005.

[3] X.L. Liang, S.S. Zhong, W. Wang, Tapered CPW-fed printed monopole antenna, Microw. Optical Technol. Lett. 48(7): 1242-1244, 2006.

[4] A.A.R. Saad, M.M.M. Ali, E.E.M. Khaled, Prediction formulas for a notched frequency response of a printed ultra-wideband antenna loaded notching resonators, The Journal of Engineering: 1-3, 2013.

[5] N. H. M. Sobli, H. E. Abd-El-Raouf, Design of a compact printed band-notched antenna for ultra wideband communications, Progress In Electromagnetics Research M. 3: 57-78, 2008.

[6] R. Fallahi, A.-A. Kalteh, M. G. Roozbahani, A novel UWB elliptical slot antenna with band-notched characteristics, Progress In Electromagnetics Research. 82: 127-136, 2008.

[7] J.B. Jiang, Y. Song, Z. H. Yan, X. Zhang, W. Wu, Band-notched UWB printed antenna with an invertedL-slotted ground, Microw. Optical Technol. Lett. 51(1): 260-263, 2009.

[8] K.-H. Kim, Y.-J. Cho, S.-H. Hwang, S.-O. Park, Bandnotched UWB planar monopole antenna with two parasitic patches, Electron. Lett. 41(14): 783-785, 2005.

[9] W.-M. Li, T. Ni, T. Quan, Y.-C. Jiao, A compact CPWfed UWB antenna with WiMAX-band notched characteristics, Progress In Electromagnetics Research Letters. 26: 79-85, 2011.

[10] S. K. Mishra, J. Mukherjee, Compact printed dual bandnotched U-shaped UWB antenna, Progress In Electromagnetic Research C. 27: 169-181, 2012.

[11] M. M. Sharma, J. K. Deegwal, M. C. Govil, A. Kumar, Compact printed ultra-wideband antenna with two notched stop bands for WiMAX and WLAN, Int. J. of Applied Electromagnetics and Mechanics. 47(2): 523532, 2015.

[12] Q.-X. Chu, Y.-Y. Yang, 3.5/5.5 GHz dual band-notch ultra-wideband antenna, Electron. Lett. 44(3): 172-174, 2008.

[13] K.S. Ryu, A.A. Kishk, UWB antenna with single or dual band-notches for lower WLAN band and upper WLAN band, IEEE Trans. Antennas Propag. 57(12): 3942-3950, 2009.

[14] J.-Y. Deng, Y.-Z. Yin, S.-G. Zhou, Q.-Z. Liu, Compact ultra-wideband antenna with tri-band notched characteristic, Electron. Lett. 44(21): 1231-1233, 2008.

[15]C.-M. Luo, J.-S. Hong, H. Xiong, A tri-notched UWB antenna with low mutual coupling between the bandnotched structure, Radioengineering. 22(4): 1233-1238, 2013.

[16] Q. Wang, Y. Zhang, Design of a compact UWB antenna with triple band notched characteristics, Int. J. of Antennas and Propagation. 2014: Article ID 892765, 2014.

[17] M. M. Sharma, J. K. Deegwal, M. C. Govil, A. Kumar, An extremely wideband planar monopole antenna with triple notched stop bands, Proc. of Asia-Pacific Microwave Conference, Melbourne, Australia, pp. 327329, 2014.

[18]Z. Wang, J. Liu, Y. Yin, Triple band-notched UWB antenna using novel asymmetrical resonators, Int. J. Electron. Commun. (AEU) 70(12): 1630-1636, 2016. 